\title{
Changes to Tenth-Grade Japanese Students' Identities in Mathematics Learning During the COVID-19 Pandemic
}

\author{
Yusuke Uegatani ${ }^{1 *}$ (D) Nagisa Nakawa ${ }^{2^{\star *}}$ (D), Masato Kosaka ${ }^{3}$ (D)
}

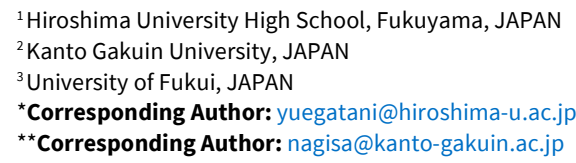

Citation: Uegatani, Y., Nakawa, N., \& Kosaka, M. (2021). Changes to Tenth-Grade Japanese Students' Identities in Mathematics Learning During the COVID-19 Pandemic. International Electronic Journal of Mathematics Education, 16(2), em0638. https://doi.org/10.29333/iejme/10905

ARTICLE INFO

Received: 15 Dec. 2020

Accepted: 6 Feb. 2021

\begin{abstract}
The current study aimed to reveal the changes to the identities of two tenth graders in mathematics learning at a Japanese high school during the COVID-19 pandemic from the perspective of learning from home versus learning in the classroom. The following research questions are raised: How has the pandemic situation affected and changed Japanese students' triadic relationship between knowledge, practice, and identity? What overlooked equity issue in this triadic relationship is caused by the pandemic? Two male students participated in and completed semi-structured interviews that asked how they managed to study at home during the school shutdown. First, we extracted from the transcript the part concerning the interviewees' difficulties in studying mathematics at home, as well as the role of mathematics lessons and their classmates. Secondly, we classified their utterances into three categories (identity, practice, and knowledge sentences), based on their grammatical patterns. The study results delineated the dynamic and complicated relationships among the three elements. Students lost opportunities to (1) obtain positive social feedback on their mathematical behaviors and (2) learn the social aspects of mathematical problem-solving, such as what strategy was socially acceptable and authorized. We also pointed out an overlooked soft equity issue; rich learning resources are substantially unavailable to students owing to the lack of appropriation of necessary knowledge and positive self-identification, despite the assurance of accessibility to such resources. We should continue to tackle helping learners construct their identities during future unexpected events.
\end{abstract}

Keywords: COVID-19, identities, appropriation of knowledge, equity, mathematics learning

\section{INTRODUCTION: SUDDEN LOSS OF SCHOOL ENVIRONMENT DUE TO THE PANDEMIC}

From March to May 2020, Japanese schools were told to temporarily shut down as the government declared a state of emergency due to the novel coronavirus COVID-19. During this shutdown, one of the authors of this paper, a mathematics teacher at a high school, instructed tenth-grade students (first year of high school) to study expansion and factorization of polynomials, properties of real numbers, and linear simultaneous inequalities by reading their mathematics textbooks and working through problems in their workbooks at home. The author noted a subtle difference in the behavior of the students under these circumstances as the quantity and quality of active online students' work differed from active offline students, that is, some active offline students were now passive online. It seemed that this new learning circumstance had changed the students. There was no change in the educational intention, but the online learning setting seemed to change the mathematics learning behavior, and this also led to questions about student identity as drastic social changes led to the changes in the school environment. The authors felt that this subtle change could be rooted in their identities regarding their mathematical learning. Thus, in this study, we investigate students' identities in relation to their appropriation of knowledge (Boaler, 2002) to gain some understanding of students' adjustment to the change from school classrooms to self-study at home, as well as address the issue of equity.

The purpose of this paper is to reveal a possible impact of the COVID-19 pandemic on the relationship between students' identities and mathematical learning practice, focusing on the Japanese educational context. Amid the turmoil over the pandemic, very little is studied about the actual picture of students' mathematical learning at their homes during school shutdown all over Japan.

\section{The Process of COVID-19 Spread Throughout Japan and the Response of Educational Authorities Since January 2020}

Japanese schools typically open the new school year in April; however, due to COVID-19, many schools were closed for a few months, after a declaration for the temporary closing of all schools from March 2 (See Table 1). 
Table 1. Percentage of schools temporarily closed

\begin{tabular}{|c|c|c|c|}
\hline School classifications & April 10 & April 22 & May 11 \\
\hline Kindergarten & $41 \%$ & $74 \%$ & $73 \%$ \\
\hline Primary School (G1-G6) & $67 \%$ & $95 \%$ & $88 \%$ \\
\hline Junior High School (G7-G9) & $67 \%$ & $95 \%$ & $88 \%$ \\
\hline Compulsory Schools (G1-G9) & $55 \%$ & $95 \%$ & $88 \%$ \\
\hline High School (G10-G12) & $65 \%$ & $97 \%$ & $89 \%$ \\
\hline Secondary School (G9-G12) & $64 \%$ & $100 \%$ & $96 \%$ \\
\hline Special Education School & $69 \%$ & $96 \%$ & $89 \%$ \\
\hline Specialized Training College & $55 \%$ & $93 \%$ & $82 \%$ \\
\hline Average & $62 \%$ & $91 \%$ & $86 \%$ \\
\hline
\end{tabular}

Source: MEXT (2020d; 2020e; 2020f)

This decision was taken to prevent significant delays in learning for students unable to sufficiently engage with coursework. The necessary measures were taken to implement adequately home-learning practices (Ministry of Education, Culture, Sports, Science, and Technology [MEXT] 2020a). MEXT launched a "portal site for learning support content during the temporary school closure" to introduce teaching materials and videos created by public institutions, children, and students that were suitable for home use as one of its measures to support learning during the temporary closure (MEXT, 2020b). According to the results of a MEXT survey of April 16, 2020, targeting 1,213 school administrations implementing temporary closures, all of them were facilitating home study through the use of textbooks and paper teaching materials. Notably, $24 \%$ implemented home-learning measures using TV broadcasts; $10 \%$ used video lessons created by their respective boards of education; and $5 \%$ used simultaneous interactive online instruction (MEXT, 2020c). On May 25, the national declaration of emergency was lifted, many schools prepared to reopen, and the summer break in August 2020 was shortened for learners to cover the required contents. The study deals with students' learning from April to June 2020, during the closure of schools in Japan.

\section{Japanese Online Learning Environment}

Information and communication technology (ICT) education in Japan has fallen behind other countries (Ogawa, 2014). The 2018 Teaching and Learning International Survey (TALIS) showed that the percentage of primary and secondary school teachers who use ICT in class increased from the percentage reported in the 2013 TALIS (MEXT \& National Institute of Educational Policy Research [NIER], 2020), although it was still low. The 2018 Program for International Student Assessment (PISA) indicated that ICT tools were rarely used in Japanese mathematics classes (NIER, 2019). Fujitani, Bhattacharya, and Akahori (2003) stated that, in Japan, ICT was inclined to be used for learning from technology, rather than learning with the aid of technology. Indeed, digital textbooks are currently more popular than ten years before; this is the same situation pointed out by this study. Fujitani, Bhattacharya, and Akahori (2003) explained that Japan has a conservative tradition of educational stakeholders strongly placing value on developing competency by interacting with others. This could be one of the many reasons why the country is behind in ICT and online learning. Tatsushima (2013) also pointed out huge gaps at various stages, among different regions, schools, and teachers within one school, and revealed the serious issue of teachers' professional development in applying ICT for teaching at any educational level. Considering these issues, it can be easily imagined that teaching online during the pandemic period was challenging for teachers and must have affected the quality of the students' learning.

During the pandemic, the majority of public primary and secondary school children in Japan did not have mathematics instruction for a few months, except for homework through self-learning. In Yokohama, for instance, children were only offered short videos online and paper-based homework, which also appeared to be the case in most other regions of Japan. Private and commercial-based coaching schools, so-called Juku, which are unofficial but popular in Japan, introduced online learning at an early stage of the pandemic. Thus, the mixed educational situation shows that the ability to use technology for learning highlights inclusion and exclusion (Chonaki \& Matos, 2013; Vithal, 2007). Exclusion means the marginalization of certain groups, for example, children of immigrants or low-income families who do not have access to the Internet. Thus, this learning crisis seriously challenged childhood equity in Japan during the pandemic period. In this study, on the other hand, our focus is not on the socially vulnerable children, but rather, typical Japanese students who are deprived of the usual learning environment at school. We would like to show that even such students were in danger of learning equity during the lockdown period.

\section{LITERATURE REVIEW}

In this section, we provide a brief review of the existing literature on mathematics education research, using identities and appropriation of knowledge by Boaler (2002) to construct our theoretical framework. Extending a situated perspective, Boaler (2002) proposed the need to explore a triadic relationship between knowledge, practice, and identity in mathematics learning.

\section{Mathematics Education Research on Identity}

Many studies (Boaler \& Selling, 2017; Darragh, 2016; Graven \& Heyd-Metzuyanim, 2019) have investigated teachers' and students' identities in the field of mathematics education research. Identity is an adjustable lens because it can focus on the human-to-human interaction level and widen to the sociopolitical context (Lerman, 2001). Identity research offers several perspectives. A broad framework can focus on the challenges of mathematics education or the experiences of specific groups of people and issues regarding equity. As Darragh (2016) mentions, vulnerable and marginalized children in underserved communities are at the center of identity research. Recently, ZDM published an intense discussion of identity in mathematics 


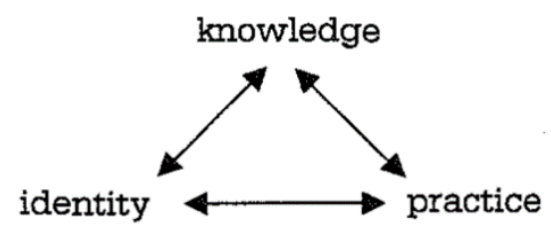

Figure 1. Relationship between identity, knowledge, and practice Source: Boaler (2002, p. 47, presented with publisher's permission)

education from various perspectives, including students' and teachers' identities (e.g., Anderson \& Wagner, 2019; Boaler \& Selling, 2017; Rosa \& Lerman, 2011; Takeuchi, 2018). Darragh (2016) examined the distribution of journal articles across regions and countries, and he did not find any articles on identity from an Asian perspective published in prestigious international journals. However, Graven and Heyd-Metzuyanim (2019) mentioned a Japanese study of mathematics education in the field of identity research. Takeuchi (2018) examined immigrant parents' participation in their primary school children's education in Japan, focusing on Filipino families. Additionally, within Japanese studies, Takahashi $(2013,2014,2015)$ published several Japaneselanguage studies dealing with identity, focusing on the process and factors of identity formation in primary school students. Nishi (2017) investigated the freshers' identity formation and suggested a hypothesis that these students have strong confidence in their identities toward mathematics, formulated during the primary and secondary mathematics education. Neither of them touched upon students' identities toward mathematics at the secondary level. The current study overcomes the imbalance in studies in the area of Asian identity formation and contributes to the research in the field of identity.

\section{Theoretical Issues of Identity Research}

Some studies in the mathematics education community discussed the concept of learner's or mathematical identities (MIs) over the last twenty years to aid understanding of learners' thinking toward the quality of learning (Radovic et al., 2018). The research stream was included in socio-cultural theories. Mathematics learners' identities have been researched intensively because it has contributed to researchers' understanding of learners' learning difficulties in mathematics, and revealed how learners conceive themselves in relation to mathematics. This contribution was useful to improve learning in mathematics. Identities research revealed, for instance, students' identities in different mathematical contents, teachers' identities, and their relationship (e.g., Hannula, 2012; Walls, 2009). These are often connected to social problems and challenges in different regions and countries (e.g., Nasir \& Cobb, 2007; Solomon, 2007). Therefore, it is connected to the issues of equity and social justice.

Together with the expansion of the studies in this domain, a meta-analysis was conducted by several studies (e.g., Darragh, 2016; Graven \& Heyd-Metzuyanim, 2019; Radovic et al., 2018) in correspondence with unsatisfactory situations of academic development for identity research in mathematics education; for example, many inconsistent definitions were used in different articles. Darragh (2016) examined a number of studies on identity in mathematics education to analyze how scholars applied identity as a concept in theoretical and empirical studies. Graven and Heyd-Metzuyanim (2019) reviewed 47 recent identity studies from 2014 to 2018 and discussed the comprehensive characteristics of these studies, in particular, the research objectives, theoretical frameworks, definitions, operationalization of identity, mathematical objects described, and the purpose of the studies, as well as discussing the future direction of identity research. First, they mention the issue of defining identity (Ntow \& Adler, 2019), also mentioned by Darragh (2016). The challenge is how to define identity without using other conceptual terms, and how to connect operative definitions and analysis (Graven \& Heyd-Metzuyanim, 2019; Radovic et al., 2018). Second, they investigate the degree to which mathematical content is included in identity research (Graven \& Heyd-Metzuyanim, 2019). To identify the degree to which mathematical content is included in identity research, we refer to the analytical lens suggested by Boaler (2002), as shown in Figure 1, because the model investigates the relation between mathematical knowledge, practices, and identities. This can assist us to identify students' challenges during the drastic social change.

Boaler proposed this triangular model in answer to the question on the relationship between identity, knowledge transfer, and mathematical capability (Boaler, 2002, p. 47). In this model, the three conceptual constructs are interrelated; however, the relationship between knowledge and identity was not well-explored, even in Baolar's later articles. Thus, the challenge raised by Graven and Heyd-Metzuyanim (2019) can only be answered by using the lens of the inter-relationship between all three, focusing on the appropriation of knowledge in particular.

\section{Appropriation of Knowledge}

As Boaler (2002) suggested, the appropriation of knowledge can be a key factor in identity formation. Appropriation means making a cultural tool one's own, and it should be distinguished from mastery and resistance of cultural tools. Appropriation of language and culture has been discussed in various studies. For example, appropriation of languages was explained by Bakhtin's (1981) dialogism and by some of the important ideas connected to language in mathematics education, as amply explained by Barwell (2016). Barwell (2016) stated that the concept of dialectic has two streams: the first is the dichotomy between the external and internal, or formal and informal mathematics languages; the second is the intertwining formations of children's development in two opposite aspects. Also, Rockwell (1996) explained the details of the appropriation of cultural meaning and practice in education, "appropriation simultaneously conveys a sense of the active/transforming nature of human agency, and the constraining/enabling character of culture" (Rockwell, 1996, p. 302). The process of the appropriation of cultural practices also could be applied to the appropriation of knowledge similarly. Takeuchi (2018) dealt with the appropriation of out-of-school resources and students' mathematical practices, in relation to positional identities. According to Bakhtin (1981), discourses are 
made from others' voices, including both verbal and written forms. One can begin absorbing and even resisting others' languages in the process of appropriation and end up reconstructing meaning using one's own words. In relation to this, Ernest (2016) pointed out that the internalization of the roles of proposer and critic are both necessary conditions for becoming a mathematician. The self-learning of mathematics requires students to dialogue with themselves through mathematical texts.

\section{THEORETICAL FRAMEWORKS AND RESEARCH QUESTIONS}

Japanese students were forced to radically alter their form of participation in their mathematics learning community because of the pandemic. Therefore, we question how the pandemic influences mathematics learning in Japan. In this section, we provide our theoretical framework and elaborate on our research questions.

Boaler's (2002) is a useful reference to comprehend the influence of the pandemic on mathematics learning. Her triadic relationship between knowledge, practice, and identity suggests that fragmentary descriptions of them may mislead us to a superficial conclusion. It is appropriate to compare the past and the current statuses of the interwoven triads for Japanese students to report the pandemic impact on their learning.

In doing so, we follow Darragh's (2016) caution that we should not draw a psychological conclusion from a sociological methodology in mathematics education research on identity. There are two distinct theoretical constructs of identity: one as an acquisition from a psychological point of view, and one as an action from a sociological point of view. To avoid confusion between them, and to keep our sociological stance, we refer to Sfard and Prusak's (2005) operative definition of identity:

[W] e suggest that identities may be defined as collections of stories about persons or, more specifically, as those narratives about individuals that are reifying, endorsable, and significant. The reifying quality comes with the use of verbs such as be, have or can rather than do, and with the adverbs always, never, usually, and so forth, that stress repetitiveness of actions.

[...] As a narrative, every identifying story may be represented by the triple ${ }_{B} A_{c}$, where $A$ is the identified person, $B$ is the author, and $\mathrm{C}$ the recipient. Within this rendering it becomes clear that multiple identities exist for any person.

(Sfard \& Prusak, 2005, pp. 16-17, italics in the original)

Based on this definition, we especially focus on self-reported identities, ${ }_{\mathrm{s}} \mathrm{S}_{\mathrm{T}}$, where $\mathrm{S}$ is a student (i.e., an interviewee) and $\mathrm{T}$ is a teacher (i.e., an interviewer), as the pandemic made students unable to interact in the classroom. In addition, the names of active students in our online learning setting are visible only to the teacher and anonymized for the students. It was particularly difficult, in principle, for a student to talk about another student's identity in our learning community. Thus, we conjecture that a seriously influenced identity-type during the pandemic could be a self-reported one. It is worth examining the qualities of learning in such a situation, as well as documenting learning crises in preparation for further similar crises.

We should not interpret the self-reported type of identities as an acquired identity, but rather as a strategy for reflecting on actions, as described below.

Metaphorically speaking, identifying is an attempt to overcome the fluidity of change by collapsing a video clip into a snapshot. [...] [M] uch of what we see now will repeat itself in a similar situation tomorrow. Based on [sic] this assumption, identity talk makes us able to cope with new situations in terms of our past experience and gives us tools to plan for the future.

(Sfard \& Prusak, 2005, p. 16, italics in the original)

The above description encouraged the authors to compare the past and current situations. Although students' identification of themselves may always be an overgeneralization from their interpretations of their past experiences, such an approach of identification is a kind of heuristic strategy for coping with new future situations. Identities, even formed in the interview, function as such.

The interview situation forces interviewees to reflect on themselves. In this sense, the identities formed in the interview cannot purely be authentic. Such identities may be the interviewees' temporal and expedient constructs for coping with the interview situation. However, we will treat such interview data as empirical evidence of one possible realization of how the interviewees identify themselves in future similar situations.

To make the interview setting more authentic, the teacher interviewed students face-to-face. An interview conducted by an unfamiliar researcher would be a novel situation for students, whereas if the interviewer is a teacher who usually communicates with the students, the interview situation becomes similar to a situation of usual educational counseling for the students, like in the usual classroom setting. The students will likely experience a similar situation in future school life. In this sense, this semistructured interview, presented as educational counseling, can be theoretically framed as a type of "Design research" (Bakker, 2018). We were interested in the students' authentic storytelling about their identities to a familiar teacher rather than an inauthentic one to unfamiliar researchers. The "authenticity bias" associated with such storytelling is welcomed in Sfard and Prusak's perspectives. For this reason, we believe that the results could provide rich educational implications for educational counseling on learning mathematics, and function as a heuristic device for the subsequent educational research (Schoenfeld, 2008). 
Table 2. Examples of problems and explanations in the workbook

\begin{tabular}{|c|c|}
\hline Types & Examples \\
\hline $\begin{array}{l}\text { Example } \\
\text { problem, } \\
\text { explanation of } \\
\text { strategy, and an } \\
\text { example answer }\end{array}$ & $\begin{array}{l}\text { Example: Solve the inequation } a x<a^{2} \text { when } a \text { is a constant. } \\
\text { Strategy: Consider different cases depending on the sign (positive, } 0 \text {, negative) of the coefficient } a \text { of } x \\
\text { Answer: } \\
\text { [1] When } a>0 \text {, divide both sides by a positive number } a \text { to obtain } x<a \\
\text { [2] When } a=0 \text {, the given inequality is } 0 \cdot x<0 \\
\text { [3] When } a<0 \text {, divide both sides by a negative number } a \text { and } x>a\end{array}$ \\
\hline $\begin{array}{l}\text { Problem in } \\
\text { Part B }\end{array}$ & $\begin{array}{l}\text { Solve the following equations and inequalities when } a \text { is a constant. } \\
\text { (1) } a x=1 \\
\text { (2) } a x \leqq 2 \\
\text { (3) } a x+6>3 x+2 a\end{array}$ \\
\hline $\begin{array}{l}\text { Problem in } \\
\text { Development }\end{array}$ & $\begin{array}{l}\text { When there are exactly five integers } x \text { that satisfy the simultaneous inequalities of } x \text {, find the range of the value of } \\
\text { the constant } a \text {. } \\
\qquad\left\{\begin{array}{c}7 x-5>13-2 x \\
x+a \geqq 3 x+15\end{array}\right.\end{array}$ \\
\hline
\end{tabular}

In addition to these theoretical perspectives, we address the delicate issue of equity in educational contexts, as well as previous identity studies (e.g., Gutiérrez, 2002, 2012). There are a variety of visible issues regarding inequity in home-learning environments between students of low- and high-income families; however, the episode presented in the introduction of this paper suggests the possibility that the unwilling alternation of learning environments leads to a new, unpredicted, and naively invisible equity issue for any students at any social status. Thus, we try to reveal the existence of an overlooked equity issue by identifying the gap between the current and past statuses of the triad relationships between knowledge, practice, and identity from the students' perspectives.

Thus, we would like to raise the following research questions: How has the pandemic situation impacted on and changed Japanese students' triad relationships between knowledge, practice, and identity? and What is an overlooked equity issue caused by the pandemic? This study focuses on students' storytelling based on previous mathematics education research on identity. Our primary interest is not in what differences objectively exist between the two learning environments, but rather, in what students' own subjective needs and challenges within such systems were invisible to adults.

\section{METHODS}

\section{Data Collection}

We interviewed two tenth-grade male students from the same high school. When the Japanese government canceled the declaration of the state of emergency over COVID-19 at the end of May 2020, the school decided to open in stages. Particularly in the first stage, the school provided students with some opportunities to use educational facilities, such as the school library, and to receive educational counseling, but it did not open any classes. At the non-compulsory stage, students could come to school to use the school facilities and talk to teachers in informal sessions. If students did not hope to attend school because of concerns about infection, they could continue to stay at home. One of the authors, a mathematics teacher, interviewed two students when they took advantage of these opportunities. They agreed to the audio recording of the interviews. Research permission was also granted by the research school. Initially, we intended to conduct interviews with four more students, but we ended up stopping these interviews for ethical reasons. The students looked too tired or nervous as a result of the abnormal circumstances; therefore, we did not request their cooperation because we were afraid that the interviews would cause additional burdens to them.

We first contacted the students online and asked two questions during the self-learning period; then, we conducted semistructured interviews when they came to school on $22^{\text {nd }}$ May 2020, when school was semi-open for those who wanted to come and talk to teachers as a special case. During the interview, the students were asked how they were learning at home. Then, the interviewer asked a flexible variety of unscripted questions depending on the responses to the first question, to explore what role mathematics classroom lessons played in mathematics learning, how classmates impact learning, what difficulties they had in appropriating mathematics knowledge at home, and what factors determined how they participated in the online learning community.

\section{Interview Background}

The academic abilities of the two participants seemed relatively higher when compared to other Japanese high school students. Because the school is a combined junior and senior high school, the interviewer had taught the two participants, Ken and Joe (pseudonyms) in junior high until March 2020. From the interviewer's perspective, they were active mathematics learners. Although they rarely asked questions outside of mathematics class, they actively discussed the content during mathematics lessons.

Their mathematics teacher, the interviewer, tended to take a problem-solving approach in the classroom because of his interest in, for example, Simon and Tzur (2004), and Harel (2008a, 2008b). Ken and Joe usually learned mathematical knowledge by solving a particular problem in class. They even learned strategic knowledge, like the proof-by-cases strategy shown in Table 2 through problem-solving. Their teacher rarely taught such strategic knowledge explicitly, before they experienced solving concrete problems. 
Table 3. Pre-interview online questionnaire

\begin{tabular}{|c|c|}
\hline Question 1 & Explain how you studied mathematics during the school shutdown. If you devised a study plan, please provide it. \\
\hline Ken's response & $\begin{array}{l}\text { I was hoping to answer the questions except for the units "numbers" and "properties of shapes," thinking that I would be } \\
\text { able to answer questions that were not taught in the workbook as the answer key would assist me in studying on my own. } \\
\text { However, I found it challenging to solve some of the problems in the workbook. I started to solve problems from the } \\
\text { workbook by referring to the two textbooks. Once I understood them, I pursued similar questions in the workbook. }\end{array}$ \\
\hline Joe's response & $\begin{array}{l}\text { I solved problems in the workbooks for school and from the commercial coaching school. I also read the handout } \\
\text { distributed online. I tried to solve problems related to factorization on my own, but with my current skills, I could not solve } \\
\text { some of the problems. }\end{array}$ \\
\hline Question 2 & $\begin{array}{l}\text { If you read Compass, which is posted on Google Classroom, please comment on its merits and areas for that you think } \\
\text { could be improved, and give reasons. }\end{array}$ \\
\hline Ken's response & I read them. I enjoy reading them because they offer a lot of fruitful pieces of advice about how to study mathematics. \\
\hline Joe's response & $\begin{array}{l}\text { They are good, particularly for complicated concepts. I feel relieved to know that a certain concept will come later and that } \\
\text { I do not need to think about it at the time. }\end{array}$ \\
\hline
\end{tabular}

In the interviews, the students often referred to the structure and content of the textbook, workbook, and learning resources that the teacher had put online. The terms "unit" and "chapter" are often used interchangeably in the classroom and by the interviewees. The first chapter of the high school mathematics textbook deals with the expansion and factorization of polynomials, properties of real numbers, and linear simultaneous inequalities. Compared to corresponding junior high content, the level is more advanced. The homework given during the shutdown concerned the first chapter and solving the corresponding problems in the workbook. The second chapter of the textbook deals with the quadratic function $y=a x^{2}+b x+c$. While in junior high level, students learned functions that were proportional to the square of $x$, i.e., $y=a x^{2}$, which were special cases of quadratic functions. Table 2 shows examples of such problems that were mentioned by the students in the interviews.

The learning resources consisted of a series of articles entitled "Compass" and were posted online by the teacher (See Appendix). The articles offer additional advanced mathematical problems and explanations to enable a deeper understanding of already known concepts, which are not usually treated by textbooks and workbooks (See Appendix). Once a Compass article was posted, students could send questions to the teacher. The answers to their questions were provided in the next Compass article.

\section{Analysis}

In studying the impact of the pandemic, first, we will extract the following topics from the interview transcriptions: the interviewees' difficulty in studying mathematics at home, and the roles of mathematics lessons and their classmates for them. Next, we will classify the interviewees' utterances into the three categories based on their grammatical patterns: identity, practice, and knowledge sentences.

Following Sfard and Prusak's (2005) definition of identity, an identity sentence has two types. At first, an identity sentence is defined as a sentence that has patterns of "I + stative verbs" or "My (property) + stative verbs." Such a sentence describes the state of the self. Following Sfard and Prusak's (2005) notation, this type of identity is expressed as s $S_{T}$, where $\mathrm{S}$ is a student (i.e., an interviewee) and $\mathrm{T}$ is a teacher (i.e., an interviewer). On the other hand, the interviewees also define the others. Second, another identity sentence is defined as a sentence that has patterns of "(someone) + stative verbs" or "(someone's property) + stative verbs." Such a sentence describes the state of the other. This type of identity is expressed as $\mathrm{s}_{T}$, where $\mathrm{S}$ is a student (i.e., an interviewee), $\mathrm{A}$ is an identified person, and $\mathrm{T}$ is a teacher (i.e., an interviewer).

A practice sentence also has two types. The first one is defined as a sentence that has a pattern of "I + action verbs." Such a sentence describes a usual way of doing something. Like the case of identity sentences, the interviewees often talk about others' practices, which is the second one. This is defined as a sentence that has a pattern of "(someone) + action verbs." All the sentences with the remaining patterns are classified into knowledge sentences. A knowledge sentence describes what an utterer knows about the subject of the uttered sentence. In the analysis, we especially focus on knowledge sentences related to mathematics and mathematics lessons.

There are exceptional procedures. We do not put any labels into the interviewee's questions. If the interviewees say, for example, that "I think that ...," then we judge the type of their sentences from their independent that-clauses. If the interviewees use the other independent clauses, such as "When ..." or "If ...," we judge not only the type of the main sentences but also that of the clauses as sentences. We neglect sentences that lack concrete information: for example, "I thought about what I could do."

By identifying what label is suitable for the uttered sentences, we construct schematic figures of Boaler's (2002) triad relationship between their knowledge, practice, and self-reported identities. We further label such identities as actual or designated, based on Sfard and Prusak's (2005) distinction. The gap between actual and designated identities is expected to reveal the impact of the pandemic on the interviewees' mathematics learning.

\section{RESULTS}

\section{Students' Responses}

During the shutdown, Ken and Joe did not actively participate in the online learning community. They did not ask their teachers any questions online. However, they filled in the online questionnaire asking how they studied mathematics during the shutdown that was sent out before the interviews. Their responses to the two questionnaire items are displayed in Table 3. 


\begin{tabular}{|c|c|c|}
\hline & $\begin{array}{c}\text { Knowledge } \\
\text { There was nothing left to do. }\end{array}$ & o do. \\
\hline \multicolumn{3}{|l|}{$[2] \nearrow$} \\
\hline \multirow{5}{*}{$\begin{array}{l}\text { Identity (AI) } \\
\text { I would not be able to finish the homework. }\end{array}$} & \multirow{3}{*}{$\leftarrow^{[1]}$} & Practice \\
\hline & & $\begin{array}{l}\text { I decided to study for an hour a day, but I did not do } \\
\text { well. }\end{array}$ \\
\hline & & $\begin{array}{l}\text { I decided to fill five pages of my notebook with } \\
\text { work. }\end{array}$ \\
\hline & \multirow[t]{2}{*}{${ }^{[2]} \rightarrow$} & $\begin{array}{l}\text { I finished every assignment I was given by the end } \\
\text { of April. }\end{array}$ \\
\hline & & I also revised all of my mistakes. \\
\hline
\end{tabular}

\section{Knowledge}

The workbook does not always have an explanation for the first problem in a unit.
There was nothing left to do.

$$
[3] \searrow
$$

Identity

$\nwarrow[4]$

\section{Practice}

I thought I would start a new unit.

Figure 2. Chronological changes and mutual relationship on knowledge, practice, and identities in the case of Ken

The following case studies provide details for the replies in Table 3.

\section{Ken's Case: Studying at Home and Its Difficulties}

Ken found it difficult to achieve his learning goals. His interview responses were consistent with his responses to the online questionnaire. He sought the best way to learn mathematics at home through trial and error. In the following transcripts, the underlined sections with (AI) mean identity sentences labeled as actual, ones with (DI) mean identity sentences labeled as designated, ones with $(\mathrm{P})$ mean practice sentences, and ones with $(\mathrm{K})$ mean knowledge sentences.

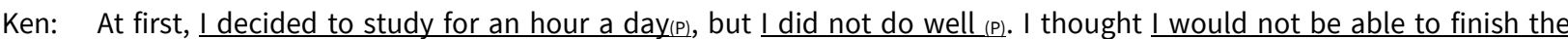
homework (Al). I decided to fill five pages of my notebook with work (P). As a result, this decision helped me to study effectively, and I finished every assignment I was given by the end of April (P). I also revised all my mistakes (P) and realized that there was nothing left to do (Al), so I thought about what I could do. I thought I would start a new unit $(\mathrm{P})$, but the workbook does not always have an explanation for the first problem in a unit (K).

Interestingly, he decided to start a new unit, the second chapter and explored the extra content that the teacher had not given as homework. This episode showed that he was an active mathematics learner, just as he was in junior high, and he maintained this attitude during the self-learning period. However, his active attitude did not necessarily lead to active participation in the online learning community. When he could not understand the textbook content, he could have asked his teacher questions, but he did not do that.

Figure 2 shows the triad relationships abstracted from the transcript above. The inner numbers in different figures show the chronological order. Figure 2 captures that Ken retrospectively connected his identity, s $\mathrm{S}_{T}$, with his practice of learning mathematics at home, and obtains new knowledge that the workbook is not necessarily useful for learning new mathematical contents when he learns alone at home.

Ken had difficulties understanding and learning the material in the new chapter. In the following transcripts, "I" represents the interviewer, and the underlines with (OP) means the others' practice sentences.

Ken: $\quad$ Regarding the new topic, my correct answer rate is not high (All).

I: I see. You described similar experiences in the questionnaire that we asked you to complete online in Google Classroom. You said that you found it difficult to study shapes on your own, hoped to be taught in class. Are there any positive points that you could talk about when you were studying numbers and number sentences?

Ken: Not particularly.

I: $\quad$ Okay, I see. Is there anything you would like to request from me regarding upcoming mathematics lessons in class?

Ken: Well, I do not have any particular requests (All).

I: I do not think that you are having any trouble in terms of your learning at home, and so you do not have requests. But I would guess that you may not be able to set your own pace when learning at home?

Ken: Oh, yes, that may be so. I do not understand the learning pace of the other students at the moment (Al).

I: $\quad$ I see. It influences you.

Ken: This could also be said about any other subject. When classroom instruction resumes, I may suddenly find that other students have managed this (OP)(DI). [Inaudible] It sounds tough. 


\begin{tabular}{|c|c|c|c|c|}
\hline & & \multicolumn{2}{|l|}{ Knowledge } & \\
\hline Identity (AI) & & & & Practice (OP) \\
\hline My correct answer rate is not high. & & $\leftarrow^{[1]}$ & & Other students have \\
\hline I do not have any particular requests. & & Identity (DI) & & managed this. \\
\hline $\begin{array}{l}\text { I do not understand the learning pace } \\
\text { of the other students at the moment. }\end{array}$ & [2]\ & $\begin{array}{l}\text { I may suddenly find that other } \\
\text { students have managed this. }\end{array}$ & $\leftarrow_{[2]}^{[2]}$ & \\
\hline
\end{tabular}

Figure 3. The impact of lack of knowledge on the learning pace on the disparity between Ken's actual and designated identities

Knowledge
Dealing with ordinal calculation, particularly in the
last section, these questions were tough.
Development seemed difficult, and this part, for
example, could be solved before moving on to Part B
by referring to the example problems here.

$[1] \nwarrow$

Identity (AI)
I would like you to teach us certain difficult
concepts in class.
I cannot understand them.

\begin{tabular}{|c|}
\hline Identity (DI) \\
I would be happy.
\end{tabular}

\begin{tabular}{|c|c|}
\hline$\leftarrow^{[1]}$ & $\begin{array}{l}\text { Practice } \\
\text { I start to solve the problems in Development. }\end{array}$ \\
\hline \multicolumn{2}{|l|}{$[2] \searrow$} \\
\hline & Practice (OP) \\
\hline$\leftarrow^{[3]}$ & $\begin{array}{l}\text { You could teach us some sort of mathematical } \\
\text { technique in class. }\end{array}$ \\
\hline
\end{tabular}

Figure 4. Ken's identity and knowledge formation from his learning practice in the pandemic

When the interviewer asked if the first chapter of the workbook was easy to study as it covered basic calculation, Ken agreed that it was. He responded to several questions regarding the pace of learning. He seemed unsure of how to establish a standard for how well he understood the content. As he generalized this to any subject, the interviewer understood that his study concerns seemed to be influenced by how well his classmates understood the content. However, the lack of knowledge on his classmates' pace of learning did not lead him to take any actions and created a gap between his actual identity in the current situation and the designated one after the pandemic (Figure 3).

I: Is there anything you don't feel confident about in the first chapter?

Ken: Well, I would like you to teach us certain difficult concepts in class (Al).

I: $\quad$ Can you give me some examples?

Ken: Well, not liner inequations, but in the first chapter, dealing with ordinal calculation, particularly the last section, these questions were tough(K), to my surprise.

Ken: In the workbook, Development seemed difficult, and this part, for example, could be solved before moving on to Part $\underline{B}$ by referring to the example problems here $(\mathrm{K})$. When I start to solve the problems in Development $(\mathrm{P}))_{2} \underline{\mathrm{I} \text { cannot }}$ understand them (Al). I would be happy (DI) if you could teach us some sort of mathematical technique in class (OP).

The workbook showed mathematics problems by the degree of the difficulty: Part A, Part B, and Development. It also showed examples of important problems with comments before introducing Part B. Ken explained that he tried to work on the problems following the order in the workbook. He argued that he could solve the problems in Part B by referring to the comments about important problems, but he had difficulty solving the problems in the Development section. His responses seemed to imply that he was able to solve Part B's problems by imitating the methods in the example problems; however, he was unable to solve the Development problems because of the lack of proper examples, as shown in Table 2. Ken's steps were to read and comprehend the explanations of strategies for solving example problems and then try to solve problems in the workbook. It is noteworthy that his primary learning strategy in the pandemic seems to be an imitation. Figure $\mathbf{4}$ shows that his practice impacts his identity and knowledge formation.

\section{Role of mathematics lessons}

When the interviewer asked if Ken needed mathematics lessons in class, he mentioned teaching methodology again.

I: In this regard, do you have any ideas? Do you think you might have done better if you had been instructed in class?

Ken: Well, yes, I felt this frequently (All. The first time you taught me was in my final year of junior high school. My teachers for the last two years used the textbook and original supplemental handouts (OP). However, you gave us a handout and 


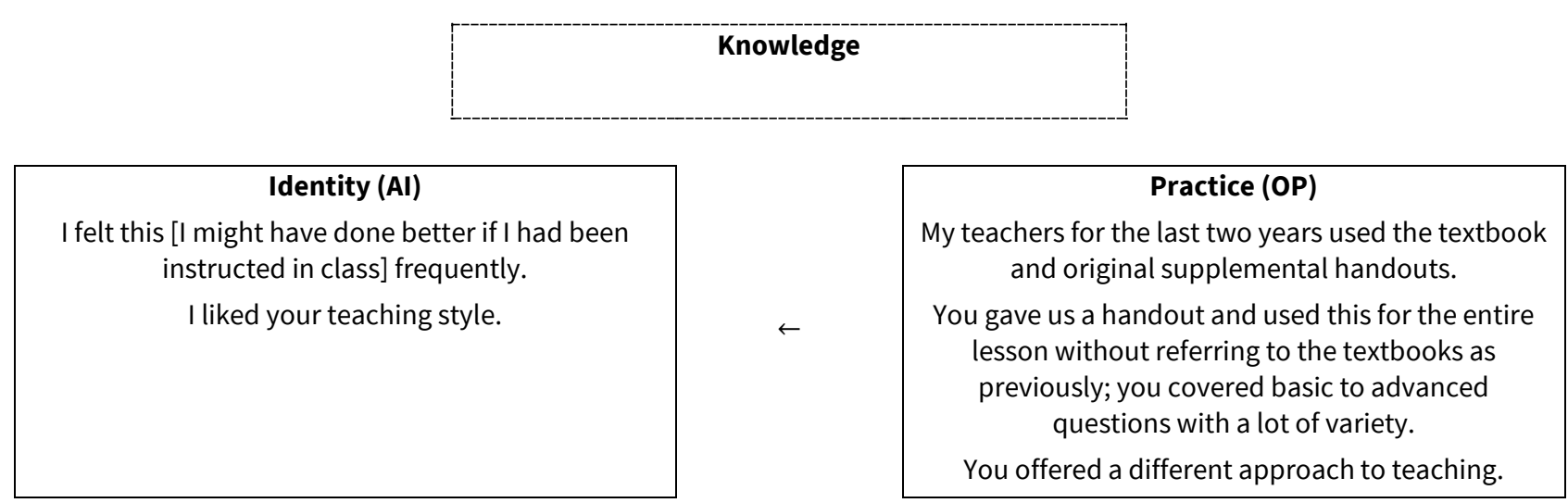

Figure 5. Ken's identity formation from his observation of his teacher's practice in the past

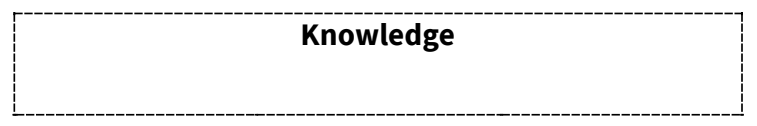

\begin{tabular}{|c|c|c|}
\hline $\begin{array}{c}\text { Identity (AI) } \\
\text { I didn't feel pressured. } \\
\text { I did not have any particular questions to ask. }\end{array}$ & $\leftarrow$ & $\begin{array}{c}\text { Practice } \\
\text { I read them. } \\
\text { I did not ask questions. }\end{array}$ \\
\hline $\begin{array}{l}\text { Identity (DI) } \\
\text { I should have some questions to ask. }\end{array}$ & $\leftarrow$ & \\
\hline
\end{tabular}

Figure 6. The disparity between Ken's actual and designated identities originated from his practice of reading the Compass articles

used this for the entire lesson without referring to the textbooks as previously; you covered basic to advanced questions with a lot of variety(OP). I liked your teaching style (A): You offered a different approach to teaching (OP).

Although Ken could not verbalize his feelings well, he thought that a particular teaching method effectively supported him when learning geometry. Since Ken did not precisely express why he preferred his teacher's method, we cannot identify what exactly impressed him. However, it could be true for him that his teacher's practice affected his actual identity. Figure $\mathbf{5}$ summarizes this impact.

\section{Factors determining participation and classmates' role}

Ken did not feel that it was necessary to actively participate in the online learning community.

I: $\quad$ Are you reading Compass? You have written some positive comments about that.

Ken: $\quad$ I read them when they are posted, but I did not ask questions (P).

I: $\quad$ Well, this was not a problem. Did you feel pressured, like you ought to ask questions?

Ken: No, I didn't (Al). I thought that I should (DI), but I did not have any particular questions to ask (Al).

His primary reason for not participating was that he had no questions. In the online questionnaire (Table 3), he responded that the Compass was useful. He was, thus, a passive receiver of information during the shutdown. Notable, he felt no pressure, and he chose to be a passive receiver. Figure 6 shows the process of disparity between his actual and designated identities through his practice of reading the Compass articles.

Ken learned from his classmates' ideas, but he was not participating in the online learning community.

I: I don't think it's a big problem that you don't have anything to ask, but I am concerned about what you think about others' ideas. Do you think the other students' ideas are good?

Ken: $\quad$ I understand their new insights, but I do not have a sharp mind (Al) when it comes to mathematics. The ideas I saw gave me new insights $(k)$, but I did not have any "aha" moment. I had no mathematical inspirations. I happen to understand these ideas (All), but that's it.

I: You mean you accepted the ideas?

Ken: If I was a mathematically inspired person $(\mathrm{DI})$, I would have this and that (DI), but in my case, I have a sort of distance from that kind of person (Al).

Ken described himself as an uninspired mathematics student compared to his classmates and had negative feelings about this. Although classmates who often asked questions online were seen as active learners from the teacher's perspective, Ken seemed to have a different conception of what an active learner does. 


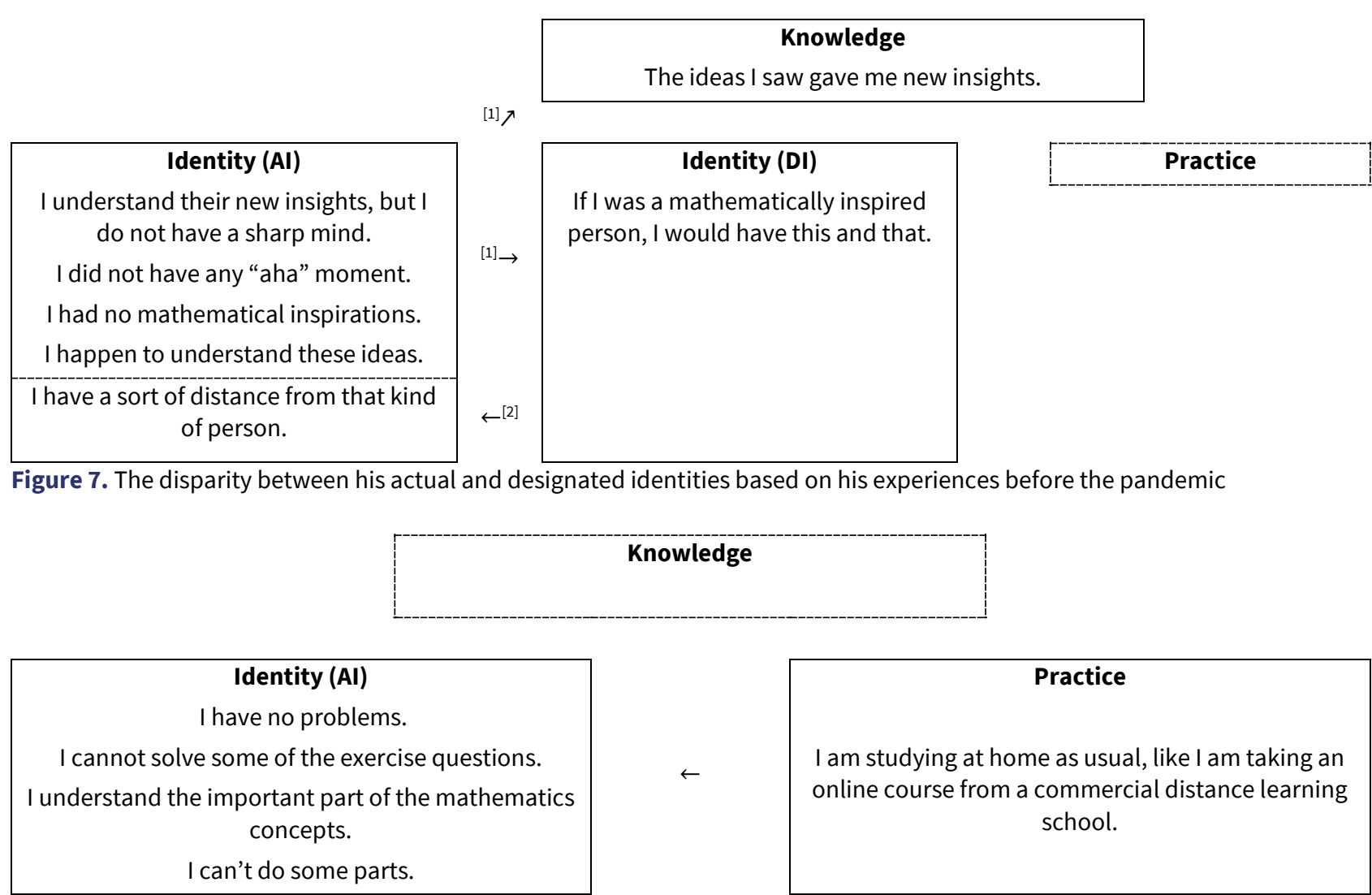

Figure 8. Joe's difficulty in learning mathematics at home during the pandemic

Figure 7 shows that the disparity between his actual and designated identities originated from his experiences in class before the pandemic. Although his hope to participate in mathematics lessons, as described in the previous subsection seems to be newly constructed during the school shutdown, his identity related to his mathematical talent is kept stable before the school shut down. He talked about himself in the transcript above. He repeatedly described himself as not innately talented. In his view, questioners in the online learning environment are talented. He incriminated his belief about his innate ability in mathematics as a cause of his passive participation in the online community.

\section{Joe's case: studying at home and its difficulties}

Joe did not demonstrate strong resistance to studying at home, but he discussed the quality of his learning outcomes.

I: How is studying at home go?

Joe: Well, actually, I am studying at home as usual, like I am taking an online course from a commercial distance learning school (P). I have no problems (Al), but I sometimes feel that I cannot solve some of the exercise questions. I understand the important part of the mathematics concepts (All), but when it comes to answering questions, I can't do some parts (Al).

Joe argued that he understood the intentions of the questions but could not solve them. His practices at home have not changed. Even before the pandemic, he had been used to taking a distance learning course for after-school activities. Note that his practices of learning had an impact on his identity (Figure 8).

He talked about mathematics learning during junior high school.

I: Do you have different feelings that you did not have with classroom learning?

Joe: Yes. Well, I feel that I was able to handle, for example, quadratic equations at the junior high school level without any difficulties at that time (A).

He pointed out the challenges of grasping problem-solving strategies, as Ken did.

I: When you were in ninth grade, what did you say? When you were taking classes, you used to have a way of solving problems without any difficulties, and what was that?

Joe: How can I say it? While I continued to solve problems, in the case of quadratic equations (P), I decided on a way of solving the problems, like whether I should apply a formula or factorize the equations (P). I did not get lost. That was how I felt (DI), but with linear inequality and questions with absolute values, I questioned myself, "Oh? Is this correct?" (P) And there were more times than previously when I did not see an important point that I used to be able to find on my own (Al). I kept questioning myself $(\mathrm{P})$, and I could not finish the problems. I found this happened often (A). 


\begin{tabular}{|c|c|c|}
\hline & Knowledge & \\
\hline Identity (DI) & \multirow{3}{*}{${ }^{[1]} \rightarrow$} & Practice \\
\hline $\begin{array}{l}\text { I was able to handle, for example, quadratic } \\
\text { equations at the junior high school level without }\end{array}$ & & $\begin{array}{l}\text { I continued to solve problems, in the case of } \\
\text { quadratic equations. }\end{array}$ \\
\hline any difficulties at that time. & & I definitely decided on a way of solving the \\
\hline \multirow[t]{2}{*}{ I did not get lost. That was how I felt } & $\leftarrow^{[2]}$ & $\begin{array}{l}\text { problems, like whether I should apply a formula or } \\
\text { factorize the equations. }\end{array}$ \\
\hline & \multirow[b]{2}{*}{$\leftarrow$} & $\begin{array}{l}\text { With linear inequality and questions with absolute } \\
\text { values, I questioned myself, "Oh? Is this correct?" }\end{array}$ \\
\hline \multirow{2}{*}{$\begin{array}{l}\text { Identity (AI) } \\
\text { There were more times than previously when I did } \\
\text { not see an important point that I used to be able to } \\
\text { find on my own. }\end{array}$} & & \\
\hline & ${ }^{[5]} \rightarrow$ & \multirow[t]{2}{*}{ I kept questioning myself. } \\
\hline $\begin{array}{l}\text { I could not finish the problems. I found this } \\
\text { happened often. }\end{array}$ & $\leftarrow^{[6]}$ & \\
\hline
\end{tabular}

Figure 9. The disparity between Joe's actual and designated identities

Joe compared the two difficulty levels of studying quadratic equations in his junior high school days and studying inequalities during the shutdown. It is reasonable to conclude that he could not grasp how to solve the more advanced problems involving inequalities using just the textbook and workbook.

Figure 9 shows the relationship between Joe's identity and practice. When solving problems of linear inequalities, he felt that he could not grasp something important to solve the problems autonomously. He could think of such important ideas by himself before the pandemic. This experience altered his practice. He frequently questioned himself on whether the solution was correct. Although he argued at the beginning of the interview that he had no problem, he began to mention the difference between his learning practices before and during the pandemic. Although they might not change overall, the gap between them becomes wider as the frequency of questioning himself becomes higher. The gradual change of practices seems to delay him from noticing the gap between his actual and designated identities.

\section{The roles of mathematics lessons and classmates for Joe}

The interviewer asked Joe why he thought he felt these difficulties. During the first half of the interview, the interviewer did not think that his difficulty came from insufficient opportunities to solve the problems. The interviewer hypothetically inferred that, instead, it was because Joe had insufficient interactions with his classmates during lessons. However, Joe was not convinced.

I: $\quad$ That could be because you are studying at home alone. Was it because you could not check how the other students were solving problems?

Joe: $\quad$ But I do not usually check the progress of others' work in class. Well, yes, I used to practice a lot and solved many advanced problems (P).

I: $\quad$ Are you talking about what you did in class?

Joe: Yes. And I think the atmosphere of classes matters (K).

He denied his classmates' influence on his mathematics learning. Rather, he argued that the role of mathematics lessons was to provide opportunities to solve some advanced problems. This supports the lack of experience in generalizing strategies that influenced his mathematics learning. These are merely his subjective reasons for why he experienced difficulties. However, his statement is crucial here. Whatever his true difficulties are, the school shutting down because of COVID-19 impacted his idea toward the role of mathematics classroom lessons for him.

Interestingly, Joe pointed out the influence of the atmosphere of the class on his mathematics learning, although he denied the direct influence of his classmates' behavior.

I: In that sense, do you have any feelings about whether you would like to participate as you did in the past?

Joe: Yes.

I: If this is true, this would not be resolved even if you could watch online clips of mathematics lessons.

Joe: Well, rather than clips, I could sort out my challenge by practicing solving problems (All):

I: Do you have a fundamental preference for mathematics classes and feel that you should make an effort to solve many problems to overcome the current situation?

Joe: Yes. I guess that I will be able to get used to these sorts of problems, and I hope to solve problems smoothly without being conscious of problem-solving strategy selection (DII). 


\begin{tabular}{|c|c|}
\hline $\begin{array}{c}\text { Identity (AI) } \\
\text { Rnowledge } \\
\text { Rather than clips, I could sort out my challenge by } \\
\text { practicing solving problems. }\end{array}$ \\
\begin{tabular}{|c|c|} 
Identity (DI) \\
I will be able to get used to these sorts of problems, \\
and I hope to solve problems smoothly without \\
being conscious of problem-solving strategy \\
selection
\end{tabular} \\
\hline
\end{tabular}

Figure 10. The disparity between Joe's relatively stable identity (actual) and relatively fragile identities (designated)

\begin{tabular}{c} 
Knowledge \\
$\begin{array}{c}\text { Learning in class is better, in terms of understanding } \\
\text { something instantly. }\end{array}$ \\
\hline
\end{tabular}

[2]

\begin{tabular}{|} 
Identity (AI) \\
$\begin{array}{c}\text { I am not able to solve the advanced ones. I cannot } \\
\text { get to that stage, I feel. }\end{array}$ \\
I had a kind of feeling that I would not get it right \\
once I got lost. \\
\hline Identity (DI) \\
I used to grasp the answers to the questions given \\
in class holistically.
\end{tabular}

Figure 11. The impact of Joe's reflection on his learning practices

\section{Practice}

I do solve the problems in the workbook for the after-school activities. I solved the fundamental problems.

Figure 10 shows that Joe's reflection on his classroom practice constructs new knowledge regarding the classroom atmosphere, and at the same time, strengthens his actual and designated identities. His impression that learning with problemsolving was more effective than learning with video clips seemed to be based on his experiences of learning practices. This actual identity seemed to remain stable before the pandemic. On the other hand, his designated identity was derived from a comparison between his learning outcomes before and during the pandemic. There seem to be both stable and fragile identities.

In the interview, he repeatedly argued for the necessity of opportunities to solve mathematical problems.

I: $\quad$ Are you solving the advanced problems at the moment?

Joe: Well, I do solve the problems in the workbook for the after-school activities. I solved the fundamental problems (P), but $\underline{I}$ am not able to solve the advanced ones. I cannot get to that stage, I feel (Al).

Joe felt it was difficult to acquire the skills to solve advanced problems. However, he did not verbalize the origin of this difficulty.

While he acknowledged the efficacy of mathematics lessons, he could not identify what aspects of the lessons had an impact on his learning.

Joe: I used to grasp the answers to the questions given in class holistically (DI), but I had a kind of feeling that I would not get it right once I got lost (All. Learning in class is better, in terms of understanding something instantly (K), when we are given a certain question that we can't completely understand as a whole.

I: You keep saying "exercises." In this case, you could solve similar problems to the ones in the workbook, or the ones in the textbook. You could upload them on Google Classroom. This could be exactly the same as the current situation where you study at home.

Joe: Well, uh...

I: But, perhaps, it would be different from the teacher giving you some tasks to perform?

Joe: Well, I think so. I do think so.

Figure 11 shows Joe's evaluation of learning in class. His new actual identity was formed based on his experience before the pandemic, and as a result, he concluded that learning in class was better. In his opinion, learning in class assisted him in understanding questions as a whole, and helped him to grasp questions better. 


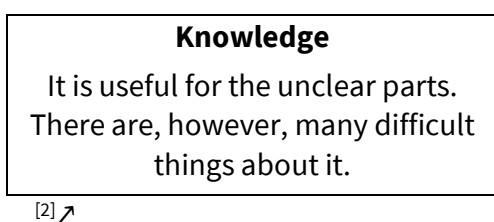

[2]

\begin{tabular}{|c|c|}
\hline $\begin{array}{c}\text { Identity (AI) } \\
\text { I feel difficult. }\end{array} \leftarrow$ Pr] & $\begin{array}{c}\text { Practice } \\
\text { I read it through. }\end{array}$ \\
\hline
\end{tabular}

Figure 12. The impact of Joe's mother on his identity and his knowledge about Compass

Table 4. Summary of the triad relationships in the case of Ken

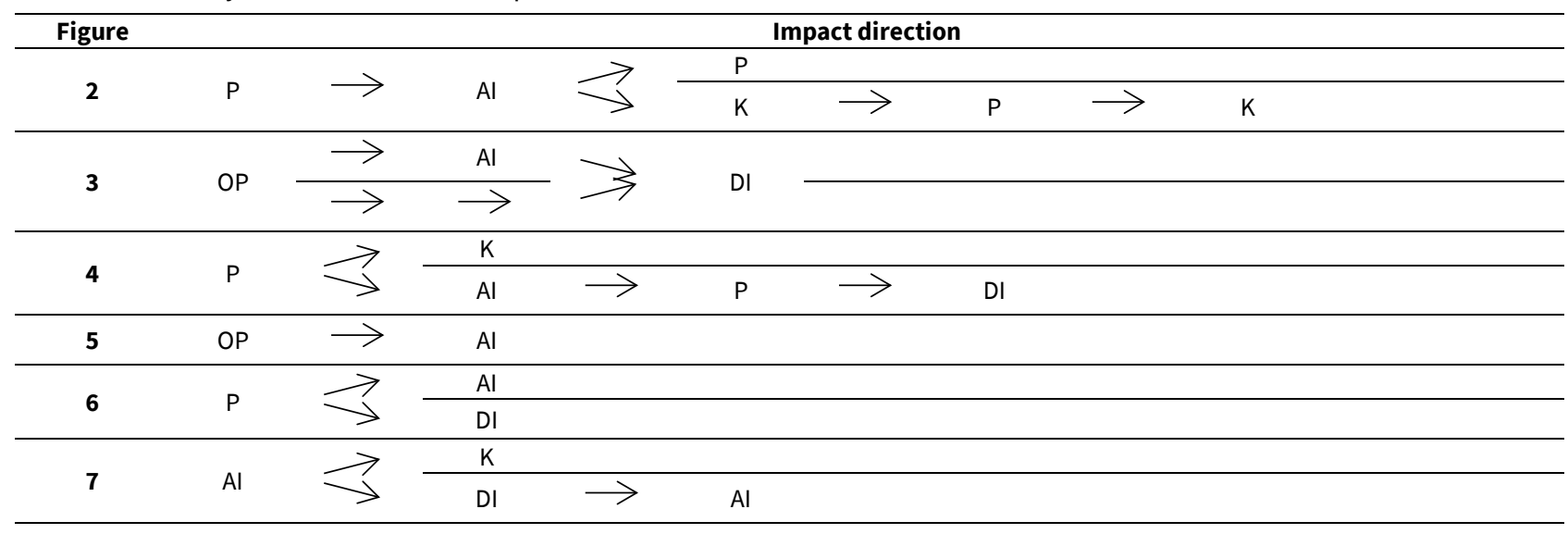

He agreed that the teacher's original problems influenced his mathematics learning. In addition, his previous comments on the atmosphere of classes suggested that learning practice in the classroom community motivated him. We should note that he could not verbalize what to do during the shutdown. The loss of the classroom learning environment had a demoralizing effect on his mathematics learning, and his problem was the failure to replicate his learning practices despite his motivation to study at home, given that this was a familiar learning circumstance. For this reason, he seemed to argue for the necessity of the teacher in the process of learning mathematics. The Compass articles did not seem very appealing to Joe, although they contained the teacher's original problems. In the following transcript, the sentences underlined with OI and OK mean the other's identity and knowledge, respectively.

I: $\quad$ Do you find Compass useful for studying?

Joe: What can I say about Compass? It is useful for the unclear parts. There are, however, many difficult things about it (K).

I: $\quad$ Well, the content, right? These questions are really advanced ones.

Joe: What can I say? When my parent reads it (OP), she says, she does not get it right (OI).

I: $\quad$ Wow, do your father or mother read it together with you?

Joe: $\quad$ My mother said that it was interesting ${ }_{(\mathrm{OK})}$, but $\underline{\text { I feel difficult (Al) }}$ when $\underline{\text { read it through}}$ (P).

He preferred the classroom atmosphere to home study. For Joe, the teacher had an impact on how he learned mathematics. It is noteworthy that his mother's opinion about Compass and the practice of reading it seem to influence his impression. Figure 12 shows the process of his identity and knowledge about Compass, which was influenced by his mother.

\section{Summary of Results}

We summarize Figures $\mathbf{2}$ to $\mathbf{1 2}$ in Tables $\mathbf{4}$ and $\mathbf{5}$. The former shows the case of Ken, and the latter, Joe. Both interviewees talk about their own identities, s $S_{T}$, in Sfard and Prusak's (2005) sense, and our interpretation of the interviews suggests the existence of Boaler's (2002) interwoven triad relationships between knowledge, practice, and identity. Note that any direction of the impact of one thing on another in Tables 4 and $\mathbf{5}$ is just one of the possible interpretations from the transcripts. We interpreted these directions based on the chronological order of the transcripts, following Sfard and Prusak's (2005) emphasis on narratives.

Describing the relationship between knowledge, practice, and identity using Boaler's (2002) triangle format, we find that the pandemic affects all three entities in a complex manner. Except for one direction, we observe all the possible direct impacts among three elements: from knowledge to practice (e.g., Figure 2), practice to identity (e.g., Figures 4 and 10), identity to knowledge (e.g., Figures 7 and 12), identity to practice (e.g., Figures 4 and 9), and practice to knowledge (e.g., Figures 2 and 10). We did not observe any direct impact from knowledge to identity in the interviewees' narratives. 
Table 5. Summary of the triad relationships in case of Joe

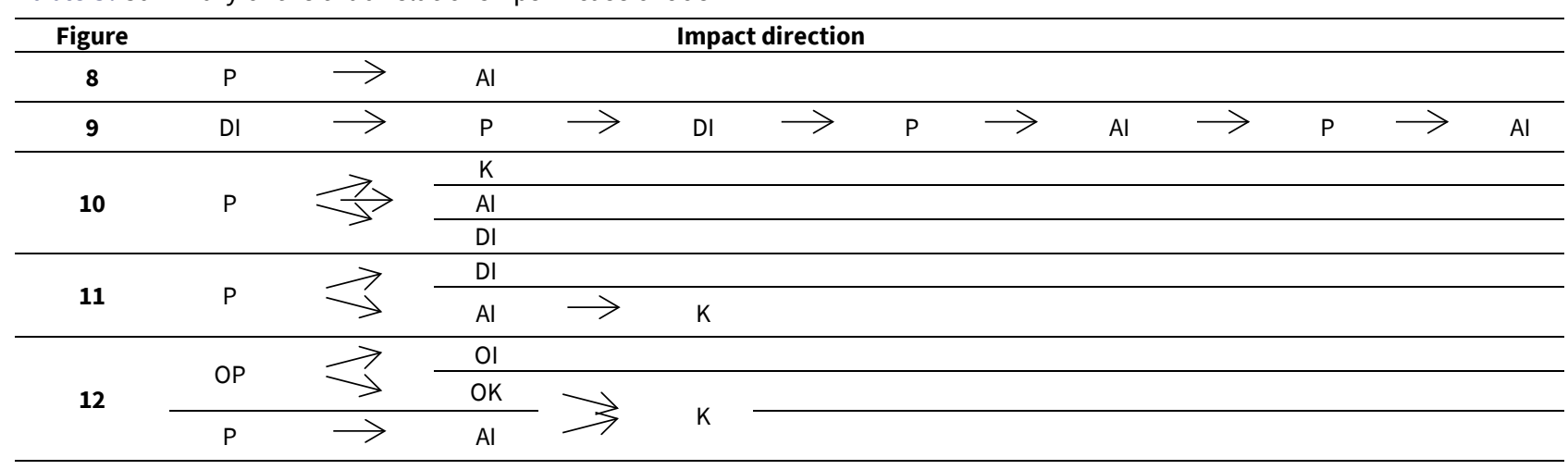

\section{DISCUSSION}

Both Ken and Joe argued that they had difficulty learning mathematics without being in classroom lessons. They identified themselves as persons who could not smoothly solve advanced mathematical problems during the school shutdown, which differed from the teacher's perspective in the daily teaching. They both expressed similar impressions implying that mathematics learning without lessons at school during the pandemic did not work well in comparison to learning at school before the pandemic. Since we do not find any direct impact of knowledge on identity in Tables $\mathbf{4}$ and 5, we can say that unexpected new learning practices in the pandemic reform their identities.

Ken did not explain why he had difficulty in understanding the advanced problems. Instead, he explained why he did not ask questions to his teacher through the online community because he was not mathematically inspired. He identified himself as such by comparing himself with his mathematically talented classmates in class before the pandemic. Based on his utterances, this negative identity limited his learning practice during the pandemic. On the other hand, he wanted to know his classmates' learning paces during the shutdown. Despite constructing his negative identity, he was not afraid to compare himself to others. Rather, he needed to compare himself to his classmates further. His identity formation seemed to depend on his classmates' behaviors. Since the school suddenly shut down, he was also suddenly deprived of an opportunity to observe his classmates' behaviors and to update his relative position in the class. Figure 3 shows the complex paths of his actual and designated identity formations. Such a designated identity emerges under the influences of his new actual identity in the pandemic and the others' practices in the future, rather than from his ideal vision.

Keeping in mind that we should interpret the concept of identity from a sociological point of view, we think that he lost a social opportunity to obtain new information on himself during the pandemic, rather than acquiring his negative identity before the pandemic. Ken's negative identity and his limitation in mathematics learning were invisible and unpredicted during the school shutdown from his teacher's point of view. If his teacher had a chance to observe Ken's mathematical behaviors directly during the shutdown, his teacher might be able to provide positive feedback to Ken. For example, since he believed that only mathematically inspired students came up with questions, his teacher could have told Ken that his feeling of difficulty itself had been a source of good mathematical questions. In addition, his classmates might learn from his questions. Ken could not appropriate "asking mathematical questions" as a good learning practice because he did not seem to have sufficient experiences of being socially accepted.

Ken seemed to need to know that his questioning was socially accepted and authorized as a good learning practice. Since Figures $\mathbf{3}$ and $\mathbf{5}$ suggest a possibility that others' practices would influence one's identity formation, we further need to explore how we can offer an alternative to the others' practices for positive identity formation in future unexpected situations like the pandemic.

Joe did mathematics exercises during the school shutdown as he usually did before the pandemic. From his point of view, the difference between such exercises before and during the pandemic was whether or not he could get used to the problems. Although Joe denied the direct influence of his classmates' behaviors on his mathematics learning in class, he needed to share his classmates' tendencies, similar to what Ken needed to know: his classmates' pace of learning. As Figure 9 shows, the disparity between his actual and designated identities became wider through questioning himself frequently. Figure 10 indicates that Joe's new knowledge about the indirect influence of classroom atmospheres is derived from his reflection on his learning practice before the pandemic.

As he reported, he often questioned himself, whether or not his strategy selection was correct while he studies alone at home. From a mathematical point of view, he should be able to judge the validity of a strategy selection only based on the contents of the mathematical problem in question. Nevertheless, he could not do that. It could be because he needed social acceptance by others, including his teacher and classmates, and authorization of his strategy selection with others. Mathematical problemsolving is not only an inquiry into mathematical truth but also a social practice at the same time. It was not sufficient for Joe to solve mathematical problems in the workbook and to experience reaching the same objective solutions as ones indicated by the workbook to identify himself as confident in problem-solving. Although an exemplary solution in the workbook indicates how to solve a corresponding mathematical problem, it does not directly indicate when to do it in such a manner (cf. Sfard \& Lavie, 2005). 
At least for Joe, appropriation of knowledge on the time when he should choose a particular problem-solving strategy does not smoothly occur without social acceptance and authorization. As Figures 10 and 11 show, his past classroom practices and current actual identities support new knowledge construction about mathematics lessons.

As reviewed earlier, Ernest (2016) suggests in theory that a mathematician internalizes conversation between a proposer and a critic. In this study, the two interviewees tried to dialogue with themselves through mathematical texts; on the other hand, they needed human resources, such as their teacher, other students, and the environment with others, to ensure various things related to their knowledge formation in the process of the appropriation of knowledge. The results of our interview suggest that the quality and the process of internalization are important in practice. The appropriation of mathematical problem-solving strategies does not only depend on mathematical and logical truths but also social acceptance or authorization.

Let us consider our research questions. First, we questioned: How has the pandemic situation impacted Japanese students triad relationships between knowledge, practice, and identity? Due to the pandemic, Ken lost an opportunity to know how he could behave in an online community for learning mathematics, and actively chose passive participation in the online community as his new practice. It is a consequence of appreciating knowledge on how to behave in mathematics learning. Joe began to question himself frequently, whether or not his strategy selection was correct, though he completed the workbook as usual. It indicated that he needed a social situation for the appreciation of strategy selection, which could lead to knowledge construction. We argued that the pandemic and school shutdown primarily affected their practices (Tables $\mathbf{4}$ and $\mathbf{5}$ ). Their knowledge and identities were reformed into complicated chain reactions, and their practices were rearranged due to their new knowledge and identities. In addition, there seems to be a mutually dependent relationship between the personal and the social: their ways of making sense of their experiences drive their next actions in the social, and social feedbacks drive their actions; for example, social acceptance or authorization frames their sense-making. For this reason, when the students were isolated from the social in the pandemic, they lost the opportunity to learn social aspects of doing mathematics at the same time. We revealed the dynamics of such an opportunity loss during the crisis, framing the interview transcripts as transitions of triad relationships between knowledge, practice, and identity.

In this sense, the more significant impact of the pandemic on students was the limitation to the interactions among the community members. This idea was proven to be true and significant on the students' side. Accessibility to mathematical contents or their teacher via the Internet, or so-called ICT facilities and virtual learning in this particular context, was not solely sufficient for the students to learn mathematics as usual, in terms of its quality. All their behaviors are implicitly and mutually assessed by each other, and also by the teacher in an ordinal classroom, whereas only the messages that active students intentionally sent were assessed in the online community. Possibilities of unexpected assessment by others seem to be an important social aspect of mathematics learning.

This study was motivated by an interest in students' identities related to mathematical learning at their homes; thus, our interviews focused primarily on their isolated identities. However, as Graven and Heyd-Metzuyanim (2019) point out in their reviews of identity research, our result suggests that we also need to consider the mutual development of students' and their teachers' identities. Otherwise, we cannot grasp actual pictures of their identity development even if our focus is on their identities at their homes. This extended perspective can be a foundation for future research in answering the original question posed by Sfard and Prusak (2005): "Why do different individuals act differently in the same situations? And why, differences notwithstanding, do different individuals' actions often reveal a distinct family resemblance?"(p. 21, italics in the original). To borrow HeydMetzuyanim's (2013) words, "a student never stays still. Something is always learned, whether it is what the teacher intends it to be, or not" (p. 360). Although the pandemic drastically changed students' learning environment, their identities have continuously developed before the change.

Second, we asked: What is an overlooked equity issue caused by the pandemic? Here, we raise a soft equity issue, which contrasts with a hard equity issue. In the online learning environments, accessibility to mathematical contents or their teacher was guaranteed for all the students. A hard equity issue, which stems from the maldistribution of learning resources, was not seriously problematic in communities, particularly for those who are accustomed to studying independently. However, the substantial availability of such resources was not uniform. We call this issue a soft equity issue. When students start to learn in new environments, their new practices are generated according to their prior knowledge and identities. A soft equity issue, then, derives from a lack of knowledge and disparities between actual and designated identities. Unfortunately, limited social feedback on limited online interactions made this issue invisible and was left unsolved among students. Not all of them were necessarily willing to enter the online community. They were forced to learn online due to the pandemic. We believe that educational research must treat this phenomenon as an equity issue and continue to investigate how to support such students in future similar situations.

A possible future research task is to reveal the influence of socio-cultural backgrounds on this soft equity issue. For example, Japanese people tend not to claim their opinions strongly, in general. Thus, it is possible that such socio-cultural backgrounds further restrict Japanese students' mathematics learning via the Internet. Learning with others is significant for students, particularly in socio-cultural situations where the others' thinking and behaviors strongly influence others, like in Japan (Meyer, 2016). This result could be very unique compared to the other regions, as the socio-cultural contexts are very different even among Asian countries as Meyer (2016) explained. Thus, a soft equity issue in Japan might occur differently than in the other countries. 


\section{CONCLUSIONS}

The COVID-19 pandemic suddenly deprived Japanese students of their ordinary classroom learning environment, where they mutually learn and acquire mathematical knowledge and experiences. The authors' exploration of how this affected their mathematics education sheds new light on equity issues, particularly soft equity issues, which were also embedded into the sociocultural characteristics. These characteristics influencing identities and practices are very different from other cultural sites. However, the finding that problem-solving in mathematics needs others' interactions, could be universally significant. Moreover, the study delineated the dynamic relationship between knowledge, practice, and identity, framing it as Boaler's (2002) triangle with Sfard and Prusak's (2005) discursive approach. Students' difficulties in learning mathematics during the pandemic are welldocumented in this combined framework.

We are aware that our sample is limited and ungeneralizable. In addition, since our findings depend on the interviewees' verbalization, more evidence is required through triangulation from a methodological perspective. These research limitations, which are due to the COVID-19 pandemic, should be overcome in future research. However, we believe that the Japanese students' self-reports regarding their difficulties with studying mathematics in unprecedented circumstances are unique and provide insights for the development of mathematics education research. We hope that the soft equity issues will continue to be discussed as thoroughly and frequently as hard equity issues.

Author contributions: All authors have sufficiently contributed to the study, and agreed with the results and conclusions.

Funding: This work was supported by the Japan Society for the Promotion of Science (JSPS) KAKENHI Grant (No. 18K13162).

Declaration of interest: No conflict of interest is declared by authors.

Acknowledgements: We would like to thank the students who we interviewed, as well as the school. We also would like to thank Editage (www.editage.com) for English language editing.

\section{REFERENCES}

Anderson, A., \& Wagner, D. (2019). Identities available in intertwined discourses: Mathematics student interaction. ZDM, 51(3), 529540. https://doi.org/10.1007/s11858-019-01036-w

Bakhtin, M. (1981). The dialogic imagination: Four essays by M.M. Bakhtin. (C. Emerson \& M. Holquist, Trans.). University of Texas Press.

Bakker, A. (2018). What is design research in education. In A. Bakker (Ed.), Design research in education: A practical guide for early career researchers (pp. 3-22). Routledge. https://doi.org/10.4324/9780203701010

Barwell, R. (2016). Formal and informal mathematical discourses: Bakhtin and Vygotsky, dialogue and dialectic. Educational Studies in Mathematics, 92(3), 331-345. https://doi.org/10.1007/s10649-015-9641-z

Boaler, J. (2002). The development of disciplinary relationships: Knowledge, practice and identity in mathematics classrooms. For the Learning of Mathematics, 22(1), 42-47.

Boaler, J., \& Selling, S. K. (2017). Psychological imprisonment or intellectual freedom? A longitudinal study of contrasting school mathematics approaches and their impact on adults' lives. Journal for Research in Mathematics Education, 48(1), 78-105. https://doi.org/10.5951/jresematheduc.48.1.0078

Chonaki, A., \& Matos, A. (2013). Technology use and mathematics teaching: Teacher change as discursive identity work. Learning Media and Technology, 39(1), 1-19. https://doi.org/10.1080/17439884.2013.776076

Darragh, L. (2016). Identity research in mathematics education. Educational Studies in Mathematics, 93(1), 19-33. https://doi.org/10.1007/s10649-016-9696-5

Ernest, P. (2016). The unit of analysis in mathematics education: Bridging the political-technical divide? Educational Studies in Mathematics, 92(1), 37-58. https://doi.org/10.1007/s10649-016-9689-4

Fujitani, S., Bhattacharya, M., \& Akahori, K. (2003). ICT implementation and online learning in Japan. Educational Technology, 43(3), 33-37.

Graven, M., \& Heyd-Metzuyanim, E. (2019). Mathematics identity research: The state of the art and future directions. ZDM, 51, 361377. https://doi.org/10.1007/s11858-019-01050-y

Gutiérrez, R. (2002). Enabling the practice of mathematics teachers in context: Toward a new equity research agenda. Mathematical Thinking and Learning, 4(2/3), 145-187. https://doi.org/10.1207/S15327833MTL04023_4

Gutiérrez, R. (2012). Context matters: How should we conceptualize equity in mathematics education? In Exploring scholastic mortality among working-class and indigenous students. In B. Herbel-Eisenmann, J. Choppin, D. Wagner, \& D. Pimm (Eds.). Equity in discourse for mathematics education (pp. 17-33). Springer. https://doi.org/10.1007/978-94-007-2813-4_2

Hannula, M. S. (2012). Exploring new dimensions of mathematics-related affect: Embodied and social theories. Research in Mathematics Education, 14(2), 137-161. https://doi.org/10.1080/14794802.2012.694281

Harel, G. (2008a). DNR perspective on mathematics curriculum and instruction, Part I: Focus on proving. ZDM, 40(3), 487-500. https://doi.org/10.1007/s11858-008-0104-1

Harel, G. (2008b). A DNR perspective on mathematics curriculum and instruction. Part II: With reference to teacher's knowledge base. ZDM, 40(5), 893-907. https://doi.org/10.1007/s11858-008-0146-4 
Heyd-Metzuyanim, E. (2013). The co-construction of learning difficulties in mathematics-Teacher-student interactions and their role in the development of a disabled mathematical identity. Educational Studies in Mathematics, 83(3), 341-368. https://doi.org/10.1007/s10649-012-9457-z

Lerman, S. (2001). Cultural, discursive psychology: A sociocultural approach to studying the teaching and learning of mathematics. Educational Studies in Mathematics, 46(1-3), 87-113. https://doi.org/10.1023/A:1014031004832

Meyer, E. (2016). The culture map: Decoding how people think, lead, and get things done across cultures (English Edition). Public Affairs.

Ministry of Education, Culture, Sports, Science and Technology. (2020a). Reference information related to the curriculum associated with temporary closures of elementary, junior high, high, and special education schools to prevent the spread of COVID-19 infections. Retrieved 25 June 2020 from https://www.mext.go.jp/content/202002228-mxt_kouhou01000004520_4.pdf (In Japanese)

Ministry of Education, Culture, Sports, Science and Technology. (2020b). Opening portal site for learning support content during the temporary school closure to prevent the spread of COVID-19 infections. Retrieved 25 June 2020 from https://www.mext.go.jp/content/20200303-mxt_kouhou01-000004520_02.pdf (In Japanese)

Ministry of Education, Culture, Sports, Science and Technology. (2020c). Status of measures such as learning guidance in public schools related to temporary school closures to prevent the spread of COVID-19 infections. Retrieved 25 June 2020 from https://www.mext.go.jp/content/20200421-mxt_kouhou01-000004520_4.pdf (In Japanese)

Ministry of Education, Culture, Sports, Science and Technology. (2020d). Status of initiation of the new school year in light of measures to prevent the spread of COVID-19 infections. Retrieved 25 June 2020 from https://www.mext.go.jp/content/20200413-mxt_kouhou01-000006421_1.pdf (In Japanese)

Ministry of Education, Culture, Sports, Science and Technology. (2020e). Status of implementation of temporary school closures to prevent the spread of COVID-19 infections. Retrieved 25 June 2020 from https://www.mext.go.jp/content/20200424mxt_kouhou01-000006590_1.pdf (In Japanese)

Ministry of Education, Culture, Sports, Science and Technology. (2020f). Status of implementation of temporary school closures to prevent the spread of COVID-19 infections. Retrieved 25 June 2020 from https://www.mext.go.jp/content/20200513mxt_kouhou02-000006590_2.pdf (In Japanese)

Ministry of Education, Culture, Sports, Science and Technology and National Institute of Education Policy Research. (2020). Summary of the result in the TALIS 2018. Resource document, MEXT \& NIER. Retrieved 25 June 2020 from https://www.mext.go.jp/b_menu/toukei/data/Others/__icsFiles/afieldfile/2020/20200323_mxt_kouhou02_1349189_vol2.pdf (In Japanese)

Nasir, N. S., \& Cobb, P. (2007). Improving access to mathematics: Diversity and equity in the classroom. Multicultural education series. Teachers College Press.

National Institute of Education Policy Research (2019). Summary of the results of PISA 2018. National Institute of Education Policy Research. Retrieved 25 June 2020 from https://www.nier.go.jp/kokusai/pisa/pdf/2018/01_point.pdf (In Japanese)

Nishi, S. (2017). A study of students' identity formed through mathematics education practices: Making hypothetical identities identified in terms of habits. Journal of Japan Society of Mathematical Education: Reports of Mathematical Education, 23(2), 117-128. (In Japanese)

Ntow, F. D., \& Adler, J. (2019). Identity resources and mathematics teaching identity: An exploratory study. ZDM, 51, 419-432. https://doi.org/10.1007/s11858-019-01025-z

Ogawa, C. (2014). Concern about ICT education in the international search of OECD. Proceedings of the Third Conference of Japan Society of Digital Textbooks, pp. 13-14. https://doi.org/10.20755/jsdtp.3.0_13 (In Japanese)

Radovic, D., Black, L., Williams, J., \& Salas, C. E. (2018). Towards conceptual coherence in the research on mathematics learner identity: A systematic review of the literature. Educational Studies in Mathematics, 99(1), 21-42. https://doi.org/10.1007/s10649-018-9819-2

Rockwell, E. (1996). Keys to appropriation: Rural schooling in Mexico. In B. Levinson, D. Foley, \& D. Holland (Eds.), The cultural production of the educated person (pp. 301-324). State University of New York Press.

Rosa, M., \& Lerman, S. (2011). Researching online mathematics education: Opening a space for virtual learner identities. Educational Studies in Mathematics, 78, 69-90. https://doi.org/10.1007/s10649-011-9310-9

Schoenfeld, A. H. (2008). Research Methods in (Mathematics) Education. In L. English (Ed.), Handbook of international research in mathematics education (2nd ed., pp. 467-519). Routledge.

Sfard, A., \& Lavie, I. (2005). Why Cannot Children See as the Same What Grown-Ups Cannot See as Different?-Early Numerical Thinking Revisited. Cognition and Instruction, 23(2), 237-309. https://doi.org/10.1207/s1532690xci2302_3

Sfard, A., \& Prusak, A. (2005). Telling identities: In search of an analytic tool for investigating learning as a culturally shaped activity. Educational Researcher, 34(4),14-22. https://doi.org/10.3102/0013189X034004014

Simon, M. A., \& Tzur, R. (2004). Explicating the role of mathematical tasks in conceptual learning: An elaboration of the hypothetical learning trajectory. Mathematical Thinking and Learning, 6(2), 91-104. https://doi.org/10.1207/s15327833mtl0602_2

Solomon, Y. (2007). Not belonging? What makes a functional learner identity in undergraduate mathematics? Studies in Higher Education, 32(1), 79-96. https://doi.org/10.1080/03075070601099473 
Takahashi, H. (2013). Conditions of rustic identities children form regarding mathematics: A case of Waku. Journal of Japan Society of Mathematical Education: Reports of Mathematical Education (Supplemental Issue), 95, 127-224. (In Japanese)

Takahashi, H. (2014). Characteristics of the identities with consistencies that primary schoolers have regarding mathematics. Journal of Japan Society of Mathematical Education: Reports of Mathematical Education, 96, 97-104. (In Japanese)

Takahashi, H. (2015). Identities that a primary schooler has regarding mathematics: Relationship to the identities with affective aspect and transformation of a view of learning. Journal of Japan Society of Mathematical Education: Reports of Mathematical Education, 97, 12, 4-15. (In Japanese)

Takeuchi, A. M. (2018). Power and identity in immigrant parents' involvement in early years mathematics learning. Educational Studies in Mathematics, 97, 39-53. https://doi.org/10.1007/s10649-017-9781-4

Tatsushima, Y. (2013). The present situation of the ICT-affected educational environment, and the future outlook of ICT education. In the Information Science and Technology Association Japan (Eds.). Proceeding for the 10th Information Professional Symposium (pp. 151-156). The Information Science and Technology Association Japan. (In Japanese)

Vithal, R. (2007). The 'uncivilised' scientist. In U. Gellert \& E. Jablonka (Eds), Mathematisation and Demathematisation: Social, Philosophical and Educational Ramifications (pp. 95-105). Sense Publishers. https://doi.org/10.1163/9789460911439_007

Walls, F. (2009). Mathematical subjects: Children talk about their mathematics lives. Springer. 


\section{APPENDIX}

\section{Examples of the "Compass" Article}

Compass No. 3 (Published on 4th May 2020)

\section{Introduction}

$\mathrm{Hi}$, everyone. I am collecting questions from you for the last "Compass"; the amount of questions exceeded my expectations. Here, I will not show the new contents in the textbook, but I will show some of your questions and my comments. These questions are related to very high-level mathematical contents, so I would like you to make use of "Compass" for your further studies. I would also like those who did not send me any questions to read this. This will be a good reference to help you know how other students learn mathematics; it could also be a good opportunity for you to continue to study mathematics.

I have also received some questions regarding the exercise book, which I do not have on hand, so I will answer them after the Golden Week.

\section{Invitation to the trivial group}

Here is a comment from a student.

I would like to mention some contents on p. 27 of the textbook. There is a table about four arithmetic operations, and I thought, "What if I could give different ranges of numbers?" I would like to ask a question about the range of numbers with " 0 only." Can we judge writing " $\checkmark$ " and " $x$ " in the the quotient column. Is it possible to do so? At the bottom of the table, the description of " $\checkmark$ " says, "We have not considered dividing by 0. ." My conjecture is that " $\checkmark$ " and " $x$ " cannot be added.

Well, it is great that you were able to think about this for the following two reasons! First, I received this comment before the "Compass No. 2" article was issued; however, at that stage, it was good that s/he wondered whether calculations with various numbers were closed. It is very nice that you were able to achieve a deeper reading of the textbook. In self-learning, attempting to create a problem based on what you have learned is very important. The importance of the ability to generate a new mathematical problem has often been unexpectedly neglected, but "to solve advanced problems" implies composing appropriate questions by yourself and using small steps to solve entire problems. This skill of solving problems is actually nurtured by creating problems.

Second, I am pleased that s/he wrote his/her own answer and provided a rationale for it while asking me this question. If you do this, I can give concrete advice and answers that are more relevant to your problems. Of course, you may not know how to tackle the problem at all, or you may not understand the meaning of the question sentence in the first place. I think that there are various types of issues in this regard, so there may be times when you will not have any clues regarding an appropriate strategy. You may be unable to think of it at all. Therefore, you do not need to write down your own rationale and answer when asking me a question. Send the question with your own answer and rationale-but only if you can. I would be pleased if you do this.

Now, let us get back to the main subject. I would like to answer the following question: Can the quotient be marked with " $\checkmark$ " or " $x$ " within the range of the number "0 only"? The answer can be both "yes" or "no"; it depends on the way of thinking. Let me show you some ways of thinking here.

\section{(1) The idea that "after all, you should not divide by 0 "}

Ever since you learned this at elementary school, you learned that "You are not supposed to divide by 0. ." When you think of this in the range of "only 0, " there can be no possible division, so you can add neither " $\checkmark$ " nor "x." Is this the same as the questioner's idea? This idea is OK for now. However, it may be mathematically good if you would grasp the following idea.

\section{(2) Let us come back to this: Why was it not right to divide by 0 ?}

Did you learn why you should not divide by 0 from elementary and junior high school teachers? Those who are from our school and who have taken my class may remember it. Of course, there may be no reason such as "Do not break the rule until you become an adult." Instead, there is a good mathematical reason why we should not divide by 0 .

First, division is an inverse calculation with regard to multiplication. For example, the calculation to find $\square$ in " $3 \times \square=6$ " is " $6 \div$ 3." Therefore, returning to the definition of a given division-for example, " $2 \div 0$ "-it can be said that it is a calculation to find $\square$ in " $0 \times \square=2$." However, no matter what you multiply by 0 , it remains 0 and cannot become 2 . Therefore, the result of " $2 \div 0$ " cannot be calculated. This is one reason why you cannot divide anything by 0 . This case is called an "impossible" case because division itself cannot be employed here.

I wrote "this case" above. What about other cases? We were only thinking about the specific case of " $2 \div 0$." However, among other cases, there may be a number that can be divided by 0 ! The statement is "No matter what you multiply by 0 , it remains $0, "$ so if it is " $0 \div 0$," you can calculate it, isn't it? Some people may think so. However, if you want to know the value of $\square$ in " $0 \times \square=$ 0 ," you can apply any number to $\square$. In other words, the answer for " $0 \div 0$ " cannot be fixed to one. It is called "indefinite." If you try to divide it, you can do it, but the answer remains undecided.

Therefore, if you divide by 0 , it will always be either impossible or indefinite. Thus, since elementary school, you learn the rule "You cannot divide numbers by $0 . "$

However, the situation is a bit different this time. We think of "only 0 " as the range of numbers. If you want to know the value of $\square$ in " $0 \times \square=0$ " within this range, it is 0 ! The range of numbers is limited. Therefore, the answer is properly set to one, and only when the range of numbers is " 0 only," we consider "0 $\div 0=0$." If you consider this issue in this way, place a " $\mathscr{V}$ " in the quotient column. 
This issue is related to the definition of division. When considering a world where there are many numbers other than 0 , "a number divided by 0 " cannot be defined with the same meaning as "a number divided by 2 " or "a number divided by 3 "; therefore, we do not define "a number divided by 0 ." However, if you consider a world where only 0 exists, you can define division only with

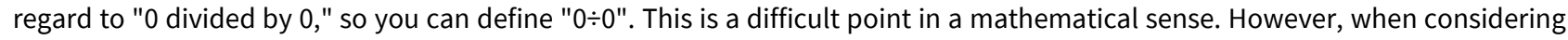
the fundamental meaning of mathematical terms, two important stages should be considered: "whether it can be defined consistently" and "whether it is actually defined."

(3) "No, in the first place, is this associated with the problem before division?": The idea that "in this case, we cannot divide by $0 . "$

A cautious person may notice this possibility. Before thinking about the meaning of division, you may have thought, "What is multiplication?" Everyone, what does multiplication mean? For example, "2×3" is three sets when we consider two pieces as a set. In this way, "0×0" means zero sets when we consider zero as a set. Are you feeling confused? Yes, to think of a set of "0" as " 1 ," there must be a "1" in this world!

If you think within the range of "0 only," you can state that multiplication cannot be defined because there is no "one" as a concept in this world, and thus, division cannot be defined. In that case, you cannot add a " $\downarrow$ " or "x" not only regarding the quotient but also regarding the product.

\section{(4) The idea that "multiplication and division are not required this time"}

The mathematical sense of anyone who noticed this possibility could be very high. In the range that includes numbers other than 0 , addition and multiplication are, of course, different calculations; however, in the range of a world where the "only 0 " condition holds, the situation could be different when considering the range. " $0+0=0$ " and " $0 \times 0=0$," so in the range of " 0 only," addition and multiplication are the same calculation! Some people may think that the meaning of the addition and multiplication is different just because addition and mulitplication are the same; however, if the calculation results are always the same, you could think that they were the same calculation. For example, I think that you learned " $x+x=2 x$ " in seventh grade. " $x+x$ " and " $2 x$ " are different calculations, but they are "the same" calculations that are connected by the equal sign. What value can be considered "the same" in $x$ ? Even if you substitute any numbers into this calculation, the same calculation result is always arrived at. If the calculation result is the same, it is regarded as being the same calculation; in fact, you have carried out this kind of mathematical operation since you were in the first year of junior high school.

Therefore, in the "0 only" range, addition and multiplication can be regarded as the same calculations, and the inverse calculations of subtraction and division are also regarded as being in the same situation. In other words, in the range of "0 only," you can also define " $0 \div 0=0-0=0$." Thus, it can be said that multiplication and division are not necessary because all multiplication and division operations can be replaced by addition and subtraction, respectively.

You may wonder as follows: well then, can we say that addition and subtraction are unnecessary when we hold multiplication and division? If that is so, you may be a genius. Yes, they are. In that case, you can write " 1 " instead of 0 . That is, instead of " $0 \times 0=$ 0 " and " $0 \div 0=0$," you can write " $1 \times 1=1$ " and " $1 \div 1=1$." Both of them imply that "when a number employs a calculation with the number itself, it results in the number itself." Now, it does not matter at all what symbol you use (e.g., 0 or 1 ); in a sense, they are all the same calculation.

The idea that "when a number employs a calculation with the number itself, it results in the number itself" may be learned through the concept of "the trivial group" when you learn mathematics in your future university. Considering the range of numbers, "only 0 " is an idea that anticipates advanced mathematics, and I think that this is very good. High school mathematics is one of the many worlds of mathematics. You cannot choose a definition other than the ones in the textbook, but when you go to university, you will think about which definition to adopt and which mathematical world to think about. You may think "I do not know," because you have lost yourself in a world of mathematics that is different from the high school mathematics you knew. This is because, in a sense, you may be too advanced for your grade. I would like you to treat this feeling of "I do not understand" positively, not negatively.

Furthermore, our high school textbook has a clever phrase: "We do not think about dividing by 0." As mentioned above, you can think of dividing by 0 , as I have indicated above. This idea is at an advanced level, so you do not have to think only at a standard level. 